\title{
Sulfoxides as response elements for fluorescent chemosensors: Does it work?
}

\author{
Jun-Sheng Chen ${ }^{a, b, d}$, Li Zhao ${ }^{a, b}$, Yang Yang $^{a}$ and Tian-Shu Chu ${ }^{a, c *}$ \\ a State Key Laboratory of Molecular Reaction Dynamics, Dalian Institute of Chemical \\ Physics, Chinese Academy of Sciences, Dalian, 116023, People's Republic of China \\ ${ }^{b}$ University of the Chinese Academy of Sciences, Beijing, 100049,People's Republic \\ of China \\ ${ }^{c}$ Institute for Computational Sciences and Engineering, Laboratory of New Fiber \\ Materials and Modern Textile, the Growing Base for State Key Laboratory, Qingdao \\ University, Qingdao, 266071, People's Republic of China \\ ${ }^{d}$ Department of Chemical Physics, Lund University, 22100 Lund, Sweden
}

Received 2 December 2014; Accepted (in revised version) 31 January 2015

Published Online 1 March 2015

\begin{abstract}
Our density functional theory (DFT)/time-dependent DFT (TDDFT) calculations for the sensing mechanism of a series of sulfoxide based metal-responsive fluorescent chemosensors, suggested that the intramolecular charge transfer (ICT) is not a reasonable mechanism for these chemosensors. The calculated electronic transition energies, the corresponding oscillator strengths of these chemosensors and the involving frontier molecular orbital analysis indicated that there is no obviously ICT state with a transition oscillator strength approaching to zero. The fluorescence quenching of these chemosensors cannot be explained by ICT process. The ground state optimized structures of chemosensors and their complexes indicated that there might be twisted excited configuration for these chemosensors and the twisted excited state configuration may response for the fluorescence quenching. The configuration change can be blocked in the $\mathrm{Zn}$ complex that is responsible for these complexes showing fluorescence emission enhancement. In order to understand the function of the sulfoxides group in these metal-responsive fluorescent chemosensors, excited state configuration optimization as well as the excited state hydrogen bond effect on the fluorescence enhancement in the aqueous solvent will be conducted.
\end{abstract}

PACS: $34.70 .+\mathrm{e} ; 42.70 .-\mathrm{a}$

Key words: Fluorescent probes; Sensing mechanism; Density functional calculations; Intramolecular charge transfer (ICT); sulfoxide moiety.

${ }^{*}$ Corresponding author. Email address: tschu@dicp.ac.cn, tschu008@163.com (T.-S. Chu) 


\section{Introduction}

Metal ions play important roles in fundamental life processes, such as catalysis, metabolism, biomineralization, osmotic regulation, signaling and so on [1]. Heavy metal ions pollution is a serious problem in some districts of the world. The released heavy metal ions from industrial waste have already polluted the water sources (groundwater, lakes, streams and rivers) in some part of the world. Hence quantitatively metal ions detection is important for understanding life processes, human health and environmental protections [1-2]. Fluorescent chemosensor for metal ion detection has attracted broad attention due to its easy operation, low cost and high sensitivity [1-2]. A large number of fluorescent chemosensors have a good performance for detecting metal ions have been reported [1-3]. Most of reported organic fluorescent chemosensors, which are based on coordination interaction between metal ions, contain nitrogen atoms which act as coordination binding atoms for metal ions [1-4]. This sort of fluorescent chemosensors are acid sensitivity and depend on the fluorescence response on nitrogen coordination chemistry [4]. These limitations can influence the performance of the fluorescent chemosensors for detecting metal ions.

Recently, Kathayat and coworker developed series of metal-responsive fluorescent chemosensors (as shown in Scheme 1, PS1-PS8) by utilizing sulfoxides as reporting functional groups [4]. These sulfoxide based fluorescent chemosensors PS1-PS8 show low fluorescence quantum yield [4]. They proposed that the fluorescence quenching phenomenon is ascribed to intramolecular charge transfer (ICT) from the sulfoxide to the

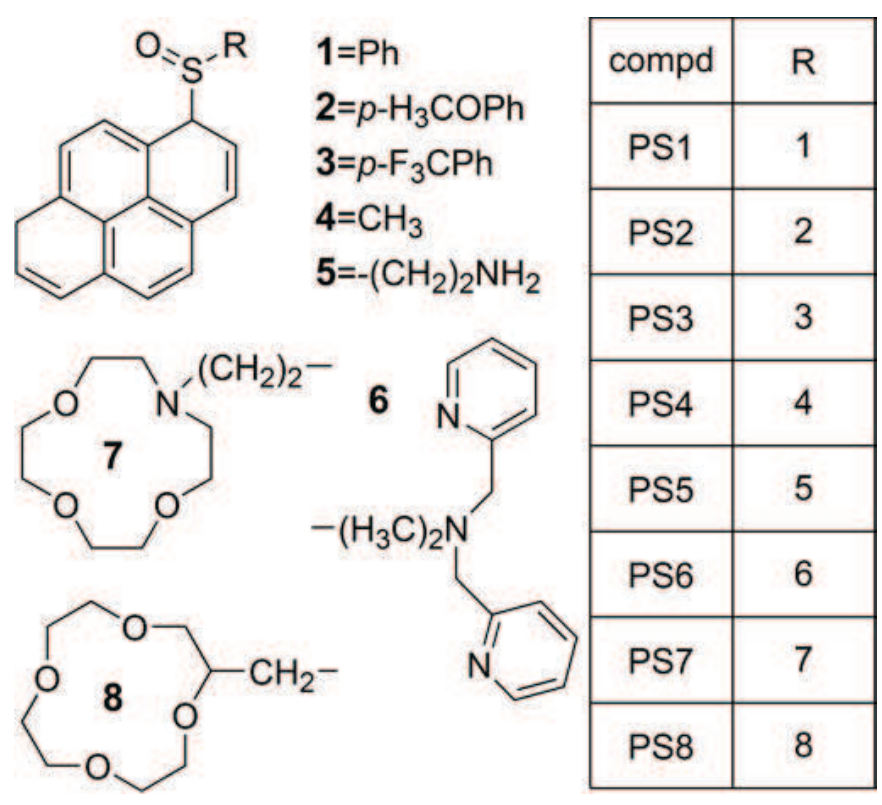

Scheme. 1: Structures of compounds PS1-PS8. 
aryl [4].They found that these fluorescent chemosensors exhibit enhanced emission upon metal binding due to the bound metal ions restrain the ICT process [4]. However, these experimental explorations provide only indirect information on the ICT process and the geometries of the studied chemosensors. Density functional theory (DFT) is a useful method to look insight into the molecular configuration [5-6]. The DFT/time-dependent functional theory (TDDFT) method has been widely used to study ICT [7-8]. excited state proton transfer (ESPT) [9-11], photo-induced electron transfer (PET) processes [1213], and DFT/TDDFT method has been proven effective in studying ICT, ESPT, PET, and other sensing mechanisms of fluorescent chemosensors [7-18]. In order to give a clear and detailed picture of the sensing mechanism of these sulfoxide based fluorescent chemosensors, we conducted a theoretical study by employing the DFT/TDDFT method to investigate both the ground and the excited states of these molecules relevant to the sensing process. We optimized the ground state structures of these fluorescent sensors and relevant metal ion coordinated complexes. We presented and analyzed the frontier molecular orbitals, electronic transition energies, oscillator strengths for the involved molecular structures.

\section{Theoretical methods}

In this contribution, all calculations presented were accomplished using the DFT/TDDFT method with the Austin-Frisch-Petersson functional with dispersion APFD [19] and TZVP basis set [20-21] by Gaussian 09 program [22]. Considering that the experiments were conducted in acetonitrile ( $\mathrm{MeCN}, \mathrm{CH}_{3} \mathrm{CN}$ ) solvent, in all calculations solvent effects were included using the integral equation formalism (IEF) [23-24] version of polarizable continuum model (PCM) [25-26] with the dielectric constant of $\mathrm{MeCN}(\varepsilon=35.7)$.For the ground state $\left(\mathrm{S}_{0}\right)$ structures, we optimized these structures without constrain. At the optimized structures, vibrational frequencies were analyzed to confirm the structures were at the minimacorresponding to the local minimal on the $S_{0}$ state. Vertical excitation energies calculations were performed from the ground optimized structure using TDDFT / APFD/ TZVP method with IEF-PCM (MeCN, $\varepsilon=35.7)$.

\section{Results and discussion}

\subsection{Optimised ground state structures compounds PS1-PS8}

The optimized ground state geometries of PS1-PS8 are shown in Fig. 1 and the important bond length, bond angle, and dihedral angle are listed in Table 1. The sulfoxide moiety is not coplanar with the pyrenyl moiety in these compounds, since the dihedral angle $\mathrm{C}_{1}-\mathrm{C}_{2}-\mathrm{S}-\mathrm{O}_{1}$ is not approach to zero degree. The dihedral angle $\mathrm{C}_{1}-\mathrm{C}_{2}-\mathrm{S}_{-} \mathrm{O}_{1}$ in PS1-PS8 is $21.5^{\circ}, 22.1^{\circ}, 22.7^{\circ}, 9.6^{\circ}, 8.8^{\circ}, 9.5^{\circ},-5.3^{\circ}$, and $-9.2^{\circ}$, respectively. The dihedral angle $\mathrm{C}_{1}-\mathrm{C}_{2}-$ $\mathrm{S}-\mathrm{O}_{1}$ can be influenced by $\mathrm{R}$ group (as shown in Scheme 1). When the $\mathrm{R}$ group contains 
Table 1: Calculated important bond lengths (in $\AA$ ) and bond angles (in degree) for the fully optimized structure of PS1-PS8 and their zinc complexes (PS1Zn-PS8Zn) in ground state $\left(\mathrm{S}_{0}\right)$.

\begin{tabular}{|c|c|c|c|c|c|c|c|c|c|c|c|c|c|c|c|c|}
\hline & PS1 & PS1Zn & PS2 & PS2Zn & PS3 & PS3Zn & PS4 & PS4Zn & PS5 & PS5Zn & PS6 & PS6Zn & PS7 & PS7Zn & PS8 & PS8Zn \\
\hline Zn-O & - & 2.01 & - & 2.02 & - & 2.01 & - & 2.00 & - & 2.00 & - & 2.01 & - & 2.03 & - & 2.04 \\
S-O & 1.53 & 1.57 & 1.53 & 1.56 & 1.52 & 1.55 & 1.53 & 1.56 & 1.53 & 1.56 & 1.53 & 1.56 & 1.53 & 1.56 & 1.53 & 1.56 \\
$\mathrm{C}^{2}-\mathrm{S}$ & 1.82 & 1.79 & 1.82 & 1.79 & 1.82 & 1.79 & 1.82 & 1.79 & 1.82 & 1.80 & 1.82 & 1.79 & 1.82 & 1.79 & 1.82 & 1.80 \\
$\mathrm{~S}^{2} \mathrm{C}^{3}$ & 1.82 & 1.81 & 1.81 & 1.80 & 1.82 & 1.81 & 1.82 & 1.81 & 1.83 & 1.83 & 1.83 & 1.83 & 1.84 & 1.82 & 1.83 & 1.82 \\
$\mathrm{C}^{1}-\mathrm{C}^{2}-\mathrm{S}$ & 116.6 & 113.5 & 116.8 & 112.2 & 116.6 & 111.8 & 116.8 & 112.7 & 116.8 & 112.0 & 116.8 & 118.2 & 120.4 & 120.0 & 116.9 & 118.2 \\
$\mathrm{C}^{2}-\mathrm{S}-\mathrm{C}^{3}$ & 95.5 & 101.2 & 96.1 & 102.4 & 95.1 & 102.2 & 96.5 & 100.9 & 95.9 & 101.1 & 91.0 & 100.1 & 92.5 & 100.8 & 95.8 & 99.1 \\
$\mathrm{C}^{1}-\mathrm{C}^{2}-\mathrm{S}-\mathrm{O}^{1}$ & 21.5 & 127.5 & 22.1 & 117.5 & 22.7 & 115.1 & 9.6 & 134.1 & 8.8 & 130.1 & 9.5 & 143.6 & -5.3 & -47.1 & -9.2 & -18.2 \\
$\mathrm{C}^{1}-\mathrm{C}^{2}-\mathrm{S}-\mathrm{C}^{3}$ & -87.0 & -124.2 & -86.5 & -132.4 & -85.4 & -133.7 & -99.1 & -113.7 & -100.1 & -116.8 & -98.5 & -105.1 & 103.9 & 62.3 & 99.1 & 88.1 \\
$\mathrm{C}^{1}-\mathrm{C}^{2}-\mathrm{C}^{3}-\mathrm{C}^{4}$ & 6.6 & 155.5 & 7.8 & 145.9 & 11.8 & 145.6 & - & - & 105.6 & 79.4 & 95.8 & 46.9 & -121.8 & -140.5 & -89.6 & -97.5 \\
\hline
\end{tabular}

alkane, the dihedral angle $\mathrm{C}_{1}-\mathrm{C}_{2}-\mathrm{S}-\mathrm{O}_{1}$ is decreased. This is due to the flexibility of alkane and induce the sulfoxide moiety tend to be coplanar with pyrenyl moiety. As listed in Table 1 , the bond angles $C_{2}-S-C_{3}$ are approach to $90^{\circ}$ and dihedral angles $C_{1}-C_{2}-S-C_{3}$ are approach to $\pm 90^{\circ}$, this indicates that the $\mathrm{R}$ group is perpendicular to the pyrenyl plane.

As described in Ref 4 the fluorescence is enhanced with the adding of some kinds of metal ions, especially for $\mathrm{Zn}^{2+}$ most of these compounds show an enhanced fluorescence emission.

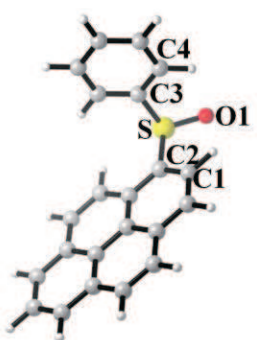

PS1

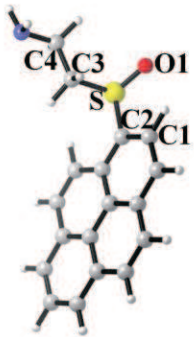

PS5

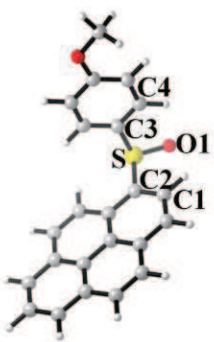

PS2

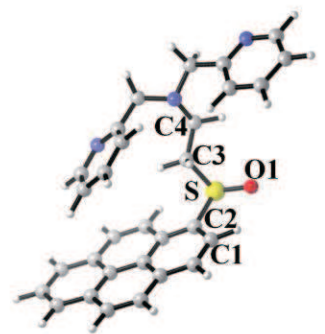

PS6

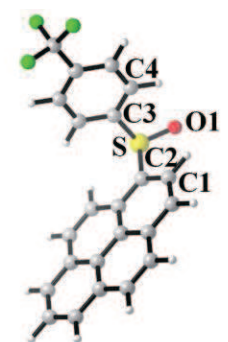

PS3

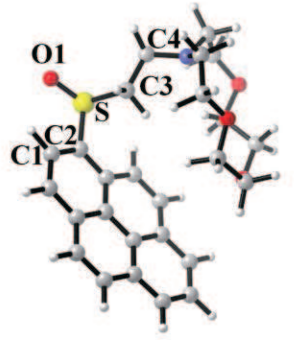

PS7

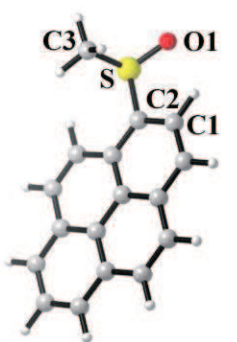

PS4

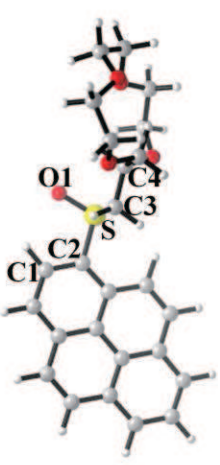

PS8

Figure 1: Views of the optimized $\mathrm{S}_{0}$ structures for compounds PS1-PS8 at the DFT/APFD/TZVP calculation level.Gray: C; white: H; red: O; blue: N; green: F; yellow: S. 
The added $\mathrm{ZnCl}_{2}$ leads to the fluorescence emission enhancement of fluorescent chemosensors PS4-PS8. In order to look insight into the interaction between the added $\mathrm{ZnCl}_{2}$ and these chemonsensors, we optimized the ground state structures of the complex between $\mathrm{ZnCl}_{2}$ and PS1-PS8, as shown in Fig. 2. The important bond length, bond angle, and dihedral angle are listed in Table 1, as a comparison with those in chemosensors PS1-PS8. In these complexes (PS1Zn-PS8Zn) the coordination bonds between zinc atom and oxygen atom are close to $2 \AA$, these are strong coordination bonds, and as a result the $\mathrm{S}-\mathrm{O}$ bonds are elongated. The $\mathrm{C}_{2}-\mathrm{S}$ and $\mathrm{C}_{3}-\mathrm{S}$ bonds in these complexes are shortened compared to that in PS1-PS8. This indicates that the C-S bond tent to have double bond property in these complexes, and it will increase the conjugation degree of these complexes. The increased conjugation degree can induce the red-shift of absorption and fluorescence emission spectra, which can be observed from the red-shifted fluorescence spectra in Ref 4 . As a consequence of the increased conjugation degree the complexes show enhanced fluorescence emission compared with PS1-PS8. The perpendicular configuration between $\mathrm{R}$ group and pyrenyl plane is broken in these complexes, which can be observed from the changed value of the bond angles C2-S-C3 (approach to $90^{\circ}$ in PS1PS8, approach to $100^{\circ}$ in PS1Zn-PS8Zn) and the dihedral angles $\mathrm{C}_{1}-\mathrm{C}_{2}-\mathrm{S}_{-} \mathrm{C}_{3} \mathrm{C}_{1}-\mathrm{C}_{2}-\mathrm{S}-\mathrm{O}_{1}$ and $C_{1}-C_{2}-C_{3}-C_{4}$ as listed in Table 1 and shown in Fig. 2. The broken perpendicular configuration between $\mathrm{R}$ group and pyrenyl plane can further increase the conjugation degree.

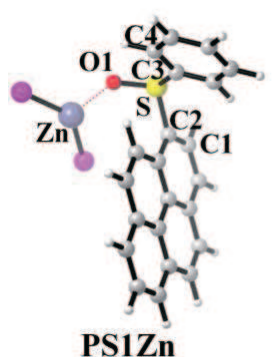

PS1Zn

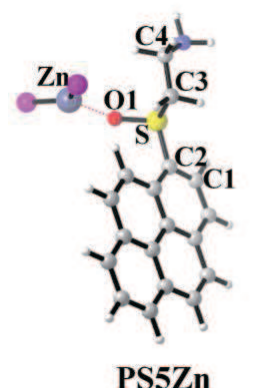

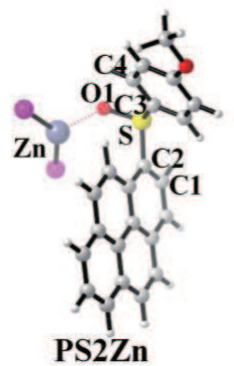

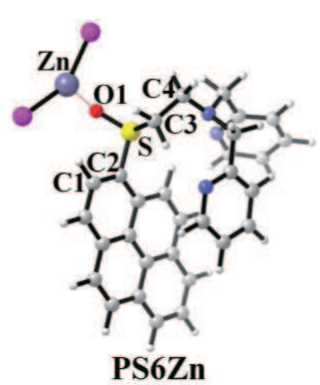

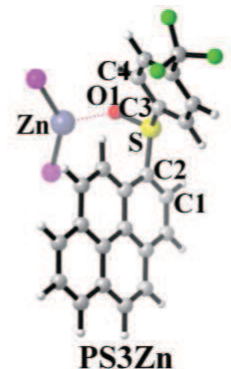

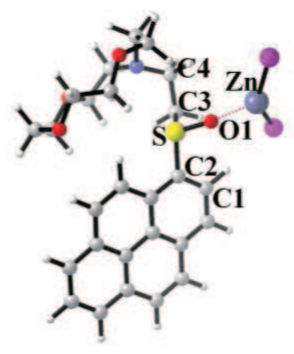

PS7Zn
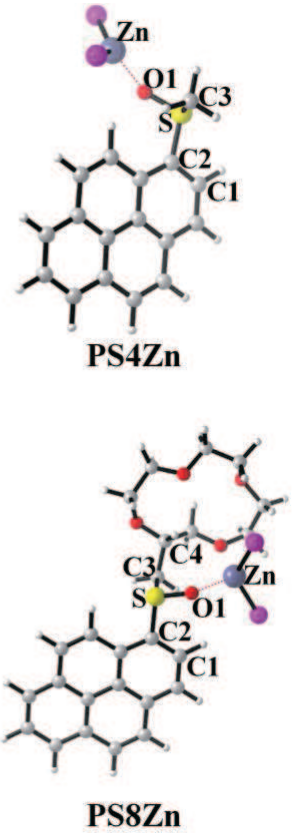

Figure 2: Views of the optimized $\mathrm{S}_{0}$ structures for complexes PS1Zn-PS8Zn at the DFT/APFD/TZVP calculation level.Gray: C; white: H; red: O; blue: N; green: F; yellow: S; dark blue: Zn; purple: $\mathrm{Cl}$. 
Table 2: Comparison of experimental and calculated absorbance band for PS1-PS8 at the TDDFT/APFD/TZVP level.

\begin{tabular}{|c|c|c|c|c|c|c|}
\hline & \multicolumn{5}{|c|}{ Theoretical data } & Experimental data \\
\hline & Electronic transition $^{a}$ & Energy $(\mathrm{nm} / \mathrm{eV})$ & $f^{b}$ & Contrib. $^{c}$ & $\mathrm{CI}^{d}$ & Absorbance band (nm) \\
\hline$\overline{\text { PS1 }}$ & $\mathrm{S}_{0} \rightarrow \mathrm{S}_{1}$ & $352(3.52)$ & 0.5084 & $\mathrm{H} \rightarrow \mathrm{L}$ & 0.94 & $\sim 353$ \\
\hline PS2 & $\mathrm{S}_{0} \rightarrow \mathrm{S}_{1}$ & $352(3.53)$ & 0.5422 & $\mathrm{H} \rightarrow \mathrm{L}$ & 0.94 & $\sim 352$ \\
\hline PS3 & $\mathrm{S}_{0} \rightarrow \mathrm{S}_{1}$ & $355(3.49)$ & 0.4913 & $\mathrm{H} \rightarrow \mathrm{L}$ & 0.94 & $\sim 353$ \\
\hline PS4 & $\mathrm{S}_{0} \rightarrow \mathrm{S}_{1}$ & $350(3.54)$ & 0.4694 & $\mathrm{H} \rightarrow \mathrm{L}$ & 0.93 & $\sim 349$ \\
\hline PS5 & $S_{0} \rightarrow S_{1}$ & $351(3.53)$ & 0.4794 & $\mathrm{H} \rightarrow \mathrm{L}$ & 0.93 & $\sim 351$ \\
\hline PS6 & $S_{0} \rightarrow S_{1}$ & $354(3.50)$ & 0.4093 & $\mathrm{H} \rightarrow \mathrm{L}$ & 0.94 & $\sim 351$ \\
\hline PS7 & $S_{0} \rightarrow S_{1}$ & $382(3.25)$ & 0.0412 & $\mathrm{H} \rightarrow \mathrm{L}$ & 0.94 & $\sim 351$ \\
\hline & $\mathrm{S}_{0} \rightarrow \mathrm{S}_{2}$ & $351(3.53)$ & 0.3696 & $\mathrm{H}-1 \rightarrow \mathrm{L}$ & 0.89 & \\
\hline PS8 & $\mathrm{S}_{0} \rightarrow \mathrm{S}_{1}$ & $352(3.52)$ & 0.5083 & $\mathrm{H} \rightarrow \mathrm{L}$ & 0.93 & $\sim 351$ \\
\hline
\end{tabular}

${ }^{a}$ Only the selected low-lying excited states are presented.

${ }^{b}$ Oscillator strength.

${ }^{c}$ Only the main configurations are presented; H, HOMO (highest occupied molecular orbital) and L, LUMO (lowest unoccupied molecular orbital).

${ }^{d}$ The CI coefficients are in absolute values.

${ }^{e}$ The experimental absorbance band taken from Ref 4 .

\subsection{UV-Vis absorption spectra and molecular orbital analysis}

We calculated the electronic transition energies and the corresponding oscillator strengths of these chemosensors (PS1-PS8) and their zinc complexes (PS1Zn-PS8Zn) using TDDFT/ APDF/TZVP method according to the above optimized geometries. The calculated electronic transition energies and the corresponding oscillator strengths $(f)$ of the low-lying singlet excited states are listed in Table 2 (for PS1-PS8) and Table 3 (for PS1Zn-PS8Zn). The calculated excited state transition energies of PS1-PS8 are close to 350nm which is agree well with the absorption spectra in the experimental results [4]. This indicates that the calculation method we adopted is reliable. Fig. 3 displays the calculated frontier molecular orbitals and the corresponding orbital energies for these chemosensor forms [see Fig.3 (a)] and these complex forms [see Fig.3 (b)]. For both chemosensor forms and complex forms, the first singlet transition $\left(\mathrm{S}_{0} \rightarrow \mathrm{S}_{1}\right)$ is assigned to HOMO $\rightarrow$ LUMO, and the corresponding orbitals with $\pi$-type symmetry are mainly localized on the pyrenyl moiety. There is an exception for PS7 and PS7Zn, the first singlet transition $\left(\mathrm{S}_{0} \rightarrow \mathrm{S}_{1}\right)$ and the second singlet transition $\left(\mathrm{S}_{0} \rightarrow \mathrm{S}_{2}\right)$ are corresponding to HOMO $\rightarrow$ LUMO and HOMO$1 \rightarrow$ LUMO, respectively. The two lowest singlet transitions of PS7 and PS7Zn possess ICT character, the electron density is distributed at crown-ether and pyrenyl moiety for HOMO and HOMO-1 orbitals, in LUMO orbital the electron density is located on the pyrenyl moiety. Hence one can see that for PS1-PS6 and PS8, the first excited state is local excited state without distinct ICT character. For PS7, the first and second excited state have ICT character, while the Zn complex PS7Zn shows ICT character in the first and 
Table 3: Comparison of experimental and calculated absorbance band for PS1Zn-PS8Zn complexes at the TD-DFT/APFD/TZVP level.

\begin{tabular}{|c|c|c|c|c|}
\hline Electronic transition $^{a}$ & Energy (nm/eV) & $\mathrm{f}^{b}$ & Contrib. $^{c}$ & $\mathrm{CI}^{d}$ \\
\hline PS1Zn $S_{0} \rightarrow S_{1}$ & $365(3.40)$ & 0.4458 & $\mathrm{H} \rightarrow \mathrm{L}$ & 0.95 \\
\hline PS2Zn $S_{0} \rightarrow S_{1}$ & $365(3.39)$ & 0.4391 & $\mathrm{H} \rightarrow \mathrm{L}$ & 0.94 \\
\hline PS3Zn $S_{0} \rightarrow S_{1}$ & $367(3.38)$ & 0.4413 & $\mathrm{H} \rightarrow \mathrm{L}$ & 0.95 \\
\hline PS4Zn $S_{0} \rightarrow S_{1}$ & $359(3.45)$ & 0.4618 & $\mathrm{H} \rightarrow \mathrm{L}$ & 0.95 \\
\hline PS5Zn $S_{0} \rightarrow S_{1}$ & $359(3.46)$ & 0.4851 & $\mathrm{H} \rightarrow \mathrm{L}$ & 0.95 \\
\hline PS6Zn $S_{0} \rightarrow S_{1}$ & $358(3.47)$ & 0.3071 & $\mathrm{H} \rightarrow \mathrm{L}$ & 0.83 \\
\hline PS7Zn $S_{0} \rightarrow S_{1}$ & $380(3.26)$ & 0.0763 & $\mathrm{H} \rightarrow \mathrm{L}$ & 0.92 \\
\hline $\mathrm{S}_{0} \rightarrow \mathrm{S}_{2}$ & $354(3.51)$ & 0.4291 & $\mathrm{H}-1 \rightarrow \mathrm{L}$ & 0.85 \\
\hline PS8Zn $S_{0} \rightarrow S_{1}$ & $352(3.52)$ & 0.5708 & $\mathrm{H} \rightarrow \mathrm{L}$ & 0.93 \\
\hline
\end{tabular}

${ }^{a}$ Only the selected low-lying excited states are presented.

${ }^{b}$ Oscillator strength.

${ }^{c}$ Only the main configurations are presented; H, HOMO (highest occupied molecular orbital) and L, LUMO (lowest unoccupied molecular orbital).

${ }^{d}$ The CI coefficients are in absolute values.

second excited state as well.

For ICT induced fluorescence quenching, the first excited state $\left(S_{1}\right)$ should be charge separate state or show ICT character, and the corresponding transition oscillator strength should be approached to zero [12-27]. As listed in Tables 2, the corresponding oscillator strengths for the electronic transitions of PS1-PS8 are not approach to zero. Even for PS7 the first singlet transition has ICT character, but the oscillator strength is $f=0.0412$. On the other hand, the first excited state of the Zn complex (PS7Zn) shows ICT character as well. Based on the calculation results it is not reasonable to propose that the ICT induce fluorescence quenching of PS1-PS8. The R group in PS1-PS8 is connected with pyrenyl moiety by two single bonds $\left(\mathrm{C}_{2}-\mathrm{S}\right.$ and $\left.\mathrm{S}-\mathrm{C}_{3}\right)$ which may rotate in the excited state, and the twisting process can induce the fluorescence quenching [28-29]. As we mentioned above, in the $\mathrm{Zn}$ complexes the bond lengths of $\mathrm{C}_{2}-\mathrm{S}$ and $\mathrm{S}-\mathrm{C}_{3}$ are shortened, which will have double bond properties. This can increase the conjugation degree of the complexes and hinder the rotation motion of the $\mathrm{R}$ group. The increased conjugation degree and blocked rotation motion may decrease the non-irradiative process of the excited state, and enhance fluorescence emission.

\section{Conclusion}

This study investigated the sensing mechanism of a series of metal-responsive fluorescent chemosensors by employing the DFT/TDDFT method. The optimized ground state structures of these chemosensors (PS1-PS8) and their zinc complexes (PS1Zn-PS8Zn) 


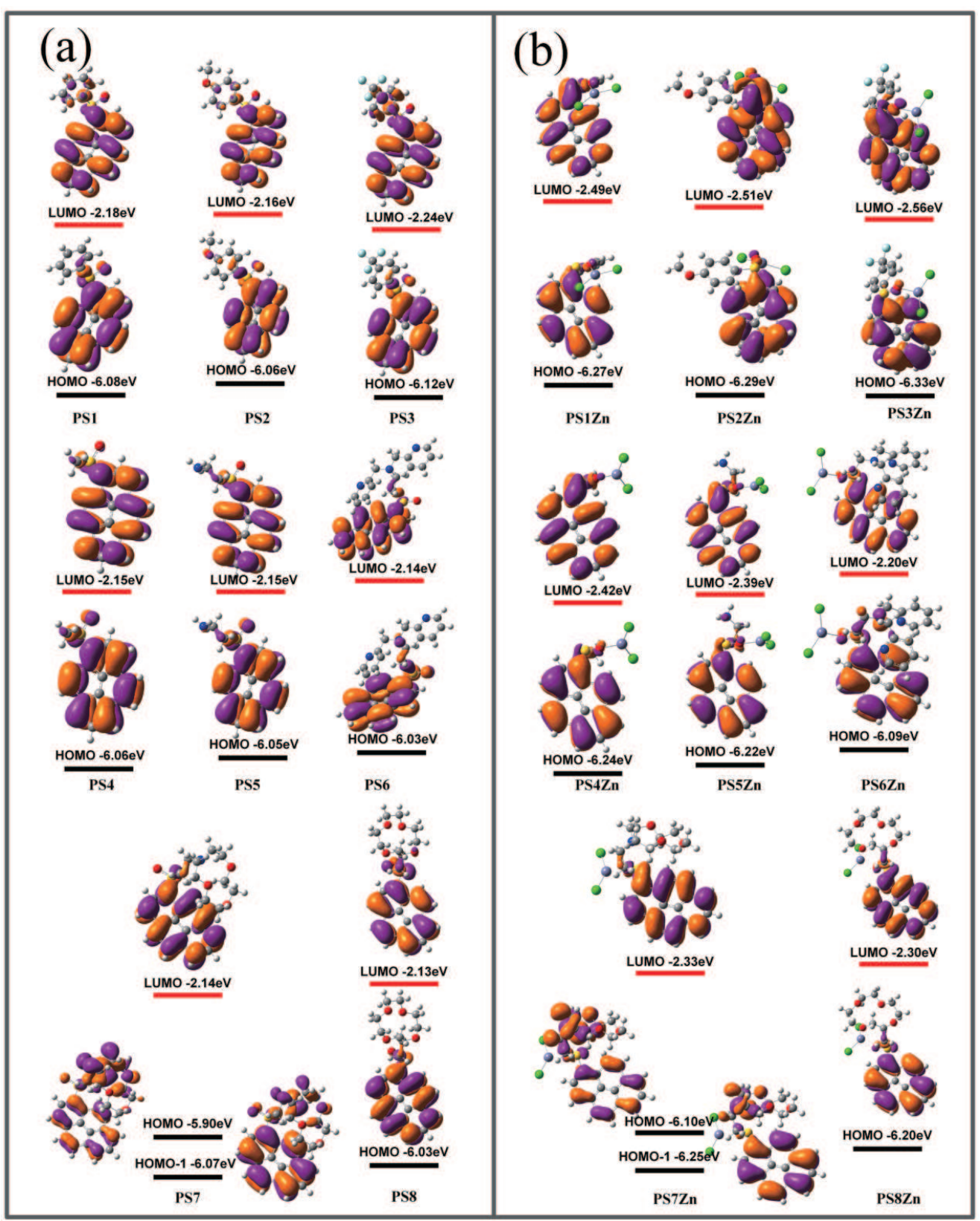

Figure 3: The calculated frontier molecular orbitals involved in the excited state transitions HOMO and LUMO for PS1-PS6 and PS8, PS1Zn-PS6Zn and PS8Zn, HOMO-1, HOMO and LUMO for PS7 and PS7Zn at DFT/APFD/TZVP level.

have been obtained. The optimized ground state structures indicate the sulfoxides can work as a reporting functional groups, which can interact with $\mathrm{ZnCl}_{2}$ and form a coordination complex, this is accordance with the experimental design. We calculated elec- 
tronic transition energies and corresponding oscillator strengths of these chemosensors and their zinc complexes by using TDDFT method. In the theoretical results there is no obviously ICT state with transition oscillator strength approaching to zero. This indicates that the proposed ICT mechanism induced fluorescence quenching is not reasonable for these chemosensors. The $\mathrm{R}$ group of these chemosensors may rotate in the excited state and there might be twisted excited state configurations, which can lead to the enhanced non-irradiative process and induce fluorescence quenching. The added $\mathrm{ZnCl}_{2}$ can coordinate with the sulfoxides group and block the rotation of the R group in the excited state, as a consequence these complexes show fluorescence emission enhancement. Additional excited state configuration optimization of these chemosenors and their $\mathrm{Zn}$ complexes as well as the excited state hydrogen bond effect on the fluorescence enhancement in the aqueous solvent will be conducted in the future to understand the function of the sulfoxides group in these metal-responsive fluorescent chemosensors.

Acknowledgments. This work is supported by National Natural Science Foundation of China (NSFC grant No. 21403226).

\section{References}

[1] Carter, K. P.; Young, A. M.; Palmer, A. E. Chem. Rev. 2014, 114, 4564-4601.

[2] Hyman, L. M.; Franz, K. J. Coordin Chem Rev 2012, 256, 2333-2356.

[3] Jeong, Y.; Yoon, J. Inorg. Chim. Acta 2012, 381, 2-14.

[4] Finney, R. S. K. a. N. S. J. Am.. Chem.. Soc. 2013, 34, 12612-12614.

[5] Chen, J. S.; Zhao, G. J.; Cook, T. R.; Sun, X. F.; Yang, S. Q.; Zhang, M. X.; Han, K. L.; Stang, P. J. J. Phys. Chem. A 2012, 116, 9911-9918.

[6] Chen, J. S.; Zhao, G. J.; Cook, T. R.; Han, K. L.; Stang, P. J. J. Am. Chem. Soc. 2013, 135, 6694-6702.

[7] Chen, J. S.; Liu, R. Z.; Yang, Y.; Chu, T. S. Theor. Chem. Acc. 2013, 133,1411.

[8] Chen, J. S.; Zhou, P. W.; Yang, S. Q.; Fu, A. P.; Chu, T. S. Phys. Chem. Chem. Phys. 2013, 15, 16183-16189.

[9] Li, G.Y.; Zhao, G. J.; Han, K. L.; He, G. Z. J. Comput.Chem. 2010, 32, 668-674.

[10] Li, G. Y.; Zhao, G. J.; Liu, Y. H.; Han, K. L.; He, G. Z. J. Comput. Chem. 2010, 31, 1759-1796.

[11] Li, G. Y.; Chu, T. S. Phys. Chem. Chem. Phys. 2011, 13, 20766-20771.

[12] Zhou, P. W.; Liu, J. Y.; Yang, S. Q.; Chen, J. S.; Han, K. L.; He, G. Z. Phys. Chem. Chem. Phys. 2012, 14, 15191-5198.

[13] Chen, J. S.; Zhou, P. W.; Li, G. Y.; Chu, T. S.; He, G. Z. J. Phys. Chem. B. 2013, 117, 5212-5221.

[14] Li, G. Y.; Song, P.; He, G. Z. Chin. J. Chem. Phys. 2011, 24, 305-310.

[15] Li, G. Y.; Li, Y. H.; Zhang, H.; Cui, G. H. Communications in Computational Chemistry 2013, 88-98.

[16] Lv, C. Y; Sun, L. J; Wang, B. Q.; Zhang, C. Y.; Zhang, J. Communications in Computational Chemistry 2013, 1, 282-296.

[17] Chen, J. S.; Zhou, P. W.; Zhao, L.; Chu, T. S. RSC Adv. 2014, 4, 254-259.

[18] Liu Lei; Yang, D. Communications in Computational Chemistry 2014, 2, 108-116.

[19] Austin, A.; Petersson, G. A.; Frisch, M. J.; Dobek, F. J.; Scalmani, G.; Throssell, K. J. Chem. Theory Comput. 2012, 8, 4989-5007.

[20] Schafer, A.; Horn, H.; Ahlrichs, R. J. Chem. Phys. 1992, 97, 2571-2577. 
[21] Schafer, A.; Huber, C.; Ahlrichs, R. J. Chem. Phys. 1994, 100, 5829-5835.

[22] Frisch, M. J.; Trucks, G. W.; Schlegel, H. B.; Scuseria, G. E.; Robb, M. A.; Cheeseman, J. R.; Scalmani, G.; Barone, V.; Mennucci, B.; Petersson, G. A.; Nakatsuji, H.; Caricato, M.; Li, X.; Hratchian, H. P.; Izmaylov, A. F.; Bloino, J.; Zheng, G.; Sonnenberg, J. L.; Hada, M.; Ehara, M.; Toyota, K.; Fukuda, R.; Hasegawa, J.; Ishida, M.; Nakajima, T.; Honda, Y.; Kitao, O.; Nakai, H.; Vreven, T.; Montgomery, J. A.; Jr.; Peralta, J. E.; Ogliaro, F.; Bearpark, M.; Heyd, J. J.; Brothers, E.; Kudin, K. N.; Staroverov, V. N.; Keith, T.; Kobayashi, R.; Normand, J.; Raghavachari, K.; Rendell, A.; Burant, J. C.; Iyengar, S. S.; Tomasi, J.; Cossi, M.; Rega, N.; Millam, J. M.; Klene, M.; Knox, J. E.; Cross, J. B.; Bakken, V.; Adamo, C.; Jaramillo, J.; Gomperts, R.; Stratmann, R. E.; Yazyev, O.; Austin, A. J.; Cammi, R.; Pomelli, C.; Ochterski, J. W.; Martin, R. L.; Morokuma, K.; Zakrzewski, V. G.; Voth, G. A.; Salvador, P.; Dannenberg, J. J.; Dapprich, S.; Daniels, A. D.; Farkas, O.; Foresman, J. B.; Ortiz, J. V.; Cioslowski, J.; Fox, D. J.; Gaussian, Inc.: Wallingford CT, 2010.

[23] Cances, E.; Mennucci, B.; Tomasi, J. J. Chem. Phys. 1997, 107, 3032-3041.

[24] Mennucci, B.; Cances, E.; Tomasi, J. J. Phy.s Chem. B 1997, 101, 10506-10517.

[25] Miertus, S.; Scrocco, E.; Tomasi, J. Chem. Phys. 1981, 55, 117-129.

[26] Cammi, R.; Tomasi, J. J. Theor. Comput. Chem. 1995, 16, 1449-1458.

[27] Ji, S. M.; Yang, J.; Yang, Q.; Liu, S. S.; Chen, M. D.; Zhao, J. Z. J. Org. Chem. 2009, 74, 48554865 .

[28] Hirayama, T.; Okuda, K.; Nagasawa, H. Chem. Sci. 2013, 4, 1250-1256.

[29] Lou, Z. R.; Yang, S. Q.; Li, P.; Zhou, P. W.; Han, K. L. Phys. Chem. Chem. Phys. 2014, 16, 3749-3756. 